\title{
Evaluation of the Genotypic Pattern of HIV-1 Resistance in AIDS Patients Failing Antiretroviral Therapy
}

\author{
Fabianna Bahia ${ }^{1}$, Célia Pedroso ${ }^{1}$, \\ Eduardo Martins Netto ${ }^{1}$, Ricardo Figueiredo ${ }^{1}$, \\ Lauro Pinto Neto ${ }^{2}$ and Carlos Brites
}

\author{
Federal University of Bahia', Salvador, BA; Santa Casa \\ de Vitória², Vitória, ES, Brazil
}

\begin{abstract}
We analyzed the first 96 patients tested for HIV resistance to antiretroviral therapy in three Brazilian states. The HIV-1 reverse transcriptase (RT) and protease (PR) were sequenced by using the ABI ViroSeq system. The drugs previously used for each patient were recorded and correlated with the mutations found in the samples. Viral load (VL) and $\mathrm{CD}_{4}$ count were also recorded. Only one patient had the wild type sequence. The most prevalent mutations were: $184 \mathrm{~V}(59 \%), 41 \mathrm{~L}(47.9 \%)$, $63 \mathrm{P}(53 \%), 215 Y(50 \%), 36 \mathrm{I}(46 \%), 10 \mathrm{I}(35 \%), 67 \mathrm{~N}(42 \%), 77 \mathrm{I}(37 \%), 90 \mathrm{M}(36 \%)$ and $210 \mathrm{~W}$ $(33 \%)$. A positive correlation between the number of previously used ARVs and the number of mutations was observed ( $p<0.05$ ). Associations between mutations and ARV drugs were identified at positions 69, 118, 184 and 215 with previous exposure to NRTI, mutations at positions 98, 100, 103, 181 and 190 with previous NNRTI use and at positions 10, 20, 30, 46, 53, 54, 71, 73, 82, 84, 88 and 90 with previous $P I$ therapy $(\mathbf{p}<0.05)$. Previous exposure to ARV drugs was associated with previous genotypic resistance to specific drugs, leading to treatment failure in HIV patients. Genotypic resistance was clearly associated with virological and immunological failure.

Key Words: HIV-1, mutations, resistance, antiretrovirals.
\end{abstract}

In patients under highly active antiretroviral therapy (HAART) for HIV-1, viral resistance is the main cause of antiretroviral therapy failure and of failure of subsequent treatment options [1-4]. Experience based on clinical trials has led to the suggestion that genotypic or phenotypic tests can help physicians guide therapeutic management of HIV-1 infected patients failing HAART [5-9].

The high replication rate of $\mathrm{HIV}-1$, in addition to its high degree of genetic variation, allows the onset of viral mutations that confer resistance to all currently available antiretroviral drugs $[10,11]$. There are more than 200 different mutations

Received on 17 February 2004; revised 23 July 2004.

Address for correspondence: Dr. Fabianna Bahia. Hospital Universitário Prof. Edgard Santos. Rua João das Botas, s/n, Canela. Zip code: 40110-160 Salvador - Bahia-Brazil. Phone: (55 71) 235-4901. Fax: (55 71) 247-2756.

E-mail: faubahia@hotmail.com

The Brazilian Journal of Infectious Diseases 2004;8(4):281-289 (C) 2004 by The Brazilian Journal of Infectious Diseases and Contexto Publishing. All rights reserved. interacting in many ways, leading to viral resistance, making the interpretation of genotypic and phenotypic tests very complex [12].

The Brazilian Ministry of Health started a program to evaluate the use of HIV genotyping in the management of antiretroviral therapy (RENAGENO). Patients failing first or second protease inhibitor (PI) containing regimens, or first non-nucleoside based therapy (NNRTI), or double therapy, are eligible for testing. We analyzed the genotypic profile of 96 patients tested for resistance in three Brazilian states in order to determine the frequency of mutations and its association with previous ARV drugs used by patients.

\section{Materials and Methods}

Patients living in the states of Bahia (BA), Sergipe (SE) (Northeast region) and Espírito Santo (ES) (Southeast region), eligible for genotyping, were tested between April 2002 and February 2003. 


\section{Laboratory evaluation}

The HIV-1 reverse transcriptase (RT) and protease (PR) genes were sequenced by using AppliedBiosystems ViroSeq 1, according to manufacturer's instructions. Demographic data, previous use of antiretrovirals, viral load and $\mathrm{CD}_{4}$ counts were recorded. Four results of viral load and $\mathrm{CD}_{4}$ count were obtained: before antiretroviral therapy, after antiretroviral therapy, after treatment failure and the lowest result of viral load and $\mathrm{CD}_{4}$ count.

\section{Statistical analysis}

Prevalence ratio was used to compare differences in frequencies. A comparison of mean $\mathrm{CD}_{4}$ count and viral load was made with the paired sample Student's $t$ test. We studied the association between resistance to ARV drug and a mutation at a given position, using a chi-square test, or a Fisher test if necessary. Logistic regression analysis was performed to study the linear relationship between the number of ARVs and mutation prevalence. We used a significance level of 0.05 and a Confidence Interval (CI) of $95 \%$.

\section{Results}

A total of 96 patients were evaluated (69\% males). The mean age was $40.7 \pm 12.5$ years. Seventy-eight $(81 \%)$ were from the state of Bahia, $15(16 \%)$ from Espírito Santo and 3 (3\%) from Sergipe. The mean $\mathrm{CD}_{4}$ counts and viral load were calculated (Table 1). All means, when compared at each time point, using paired Student's $t$ tests, were significantly different $(p<0.05)$, except for the comparison between $\mathrm{CD}_{4}$ count after treatment failure/before treatment and $\mathrm{CD}_{4}$ count after treatment/after treatment failure $(\mathrm{p}=0.99$ and $\mathrm{p}=0.24$ respectively). All viral load measurements was significantly different $(\mathrm{p}<0.05)$, except for VL before treatment and after treatment failure $(\mathrm{p}=0.65)($ Table 1$)$.

The ARV drugs that were previously used were: AZT (95.8\%), 3TC (87.5\%), DDI (72.9\%), D4T (55.2\%), IDV (53.1\%), NFV (45.8\%), RTV (34.4\%),
NVP and EFV (26\% each), SQV (19.8\%), DDC (5.2\%), APV and LPV (4.2\% each) and ABC (1\%).

Only one patient presented with a wild type sequence. The most prevalent mutations were $184 \mathrm{~V}(59 \%), 63 \mathrm{P}$ (53\%), $215 \mathrm{Y}(50 \%), 41 \mathrm{~L}(48 \%), 36 \mathrm{I}(46 \%), 67 \mathrm{~N}$ (42\%), 77I (37\%), 90M (37\%), 10I (35\%) and 210W $(33 \%)$. The frequencies of all mutations associated with ARV drugs are listed in Tables 2, 3 and 4 divided by ARV categories (NRTI, NNRTI and PI).

A positive correlation between the number of ARVs previously used and the number of mutations was observed. The mean number of NRTIs used was $3.2 \pm$ 0.9 drugs/patients. Forty-four patients used NNRTI (mean number of drugs used: $1.1 \pm 0.3 /$ patient). Among 88 patients who used PI, the mean number of drugs used was $1.8 \pm 0.9$. Figures 1 and 2 show a positive correlation with the number of drugs (NTRI and PI) used and the number of mutations identified by genotyping. Specific analysis of NNRTI was not done due to the characteristics of this class of drug (cross-resistance), which did not allow the use of a second drug after failure of the first one used.

Chi-square analysis revealed associations between some mutations and previous exposure to ARV drugs. Mutations 69D and 118I were associated with previous exposure to Stavudine (D4T), mutation $184 \mathrm{~V}$ was associated with previous exposure toLamivudine (3TC) and Didanosine (DDI), and mutation $215 \mathrm{~F} / \mathrm{Y}$, with prior use of D4T and DDI (all $p$ values $<0.05$, Table 5).

We found an association between mutations 181I/ $\mathrm{C}$ and 190A/S and exposure to Nevirapine (NVP). Although we detected a significant association between mutation 98G and NVP resistance $(\mathrm{p}=0.016)$ and mutation $100 \mathrm{I}$ and $\mathrm{EFZ}$ resistance ( $\mathrm{p}=0.001$ ), it was not possible to define the prevalence ratio, since at least one cell was equal to zero (Table 6).

Mutations at positions 10, 20, 30, 46, 53, 54, 71, $73,82,84,88$ and 90 were associated with prior therapy with specific protease inhibitors (Table 7).

\section{Discussion}

We analyzed genotyping tests for 96 patients from three Brazilian states (BA, SE and ES). Only one 
Table1. Evolution of mean $\mathrm{CD}_{4}$ count and viral load over time in patients under HAART

\begin{tabular}{lcc}
\hline Evolution & $\mathbf{C D}_{\mathbf{4}}\left(\right.$ cells $\left./ \mathbf{m m}^{\mathbf{3}}\right) \pm \mathbf{S D}$ & $\mathrm{VL}(\log \mathbf{1 0}) \pm \mathrm{SD}$ \\
\hline Before HAART & $276.7 \pm 204.2$ & $4.8 \pm 0.9$ \\
$1^{\text {st }}$ value post-HAART & $331.2 \pm 239.2$ & $4.1 \pm 0.9$ \\
Lowest value during HAART & $122.4 \pm 107.8$ & $3.4 \pm 1.0$ \\
After treatment failure & $276.9 \pm 213.3$ & $4.6 \pm 0.7$ \\
\hline
\end{tabular}

All $\mathrm{p}$ value $<0.05$ for comparison of mean $\mathrm{CD}_{4}$ and $\mathrm{VL}$ at each time point.

Table 2. Frequency of mutations according to previous use of nucleoside reverse transcriptase inhibitors (NRTI)

\begin{tabular}{|c|c|c|c|c|c|c|c|c|}
\hline \multirow{3}{*}{$\begin{array}{l}\text { No. Patients/ } \\
\text { Mutations }\end{array}$} & \multicolumn{8}{|c|}{ NRTI } \\
\hline & \multicolumn{2}{|c|}{92} & \multicolumn{2}{|c|}{70} & \multicolumn{2}{|c|}{84} & \multicolumn{2}{|c|}{53} \\
\hline & $\mathbf{A Z T}$ & $(\%)$ & DDI & $(\%)$ & 3TC & $(\%)$ & D4T & $(\%)$ \\
\hline $41 \mathrm{~L}$ & 44 & $(47.8)$ & 35 & $(50)$ & 41 & $(48.8)$ & 29 & $(54.7)$ \\
\hline $44 \mathrm{~A}$ & 1 & (1.1) & 1 & (1.4) & 1 & $(1.2)$ & 1 & (1.9) \\
\hline $44 \mathrm{D}$ & 14 & $(15.2)$ & 13 & (18.6) & 14 & (16.7) & 9 & $(17.0)$ \\
\hline $62 \mathrm{~V}$ & 2 & $(2.2)$ & 2 & $(2.9)$ & 2 & $(2.4)$ & 2 & (3.8) \\
\hline $65 \mathrm{R}$ & 2 & $(2.2)$ & 2 & $(2.9)$ & 2 & $(2.4)$ & 2 & (3.8) \\
\hline $67 \mathrm{~N}$ & 38 & $(41.3)$ & 30 & $(42.9)$ & 34 & $(40.5)$ & 26 & $(49.1)$ \\
\hline 69D & 9 & $(9.8)$ & 7 & (10) & 9 & (10.7) & 8 & $(15.1)$ \\
\hline 70R & 25 & $(27.2)$ & 20 & $(28.6)$ & 22 & $(26.2)$ & 13 & $(24.5)$ \\
\hline $74 \mathrm{I}$ & 1 & (1.1) & 2 & $(2.9)$ & 2 & $(2.4)$ & 2 & (3.8) \\
\hline $74 \mathrm{~V}$ & 5 & $(5.4)$ & 3 & $(4.3)$ & 5 & $(6.0)$ & 3 & (5.7) \\
\hline $75 \mathrm{I}$ & 5 & $(5.4)$ & 5 & (7.1) & 5 & $(6.0)$ & 3 & (5.7) \\
\hline $75 \mathrm{M}$ & 1 & (1.1) & 1 & (1.4) & 1 & $(1.2)$ & 1 & (1.9) \\
\hline $75 \mathrm{~T}$ & 1 & (1.1) & 1 & (1.4) & 1 & $(1.2)$ & 1 & (1.9) \\
\hline $77 \mathrm{~L}$ & 1 & (1.1) & 1 & (1.4) & 1 & $(1.2)$ & 1 & (1.9) \\
\hline $115 \mathrm{~F}$ & 1 & (1.1) & 1 & (1.4) & 1 & $(1.2)$ & 1 & (1.9) \\
\hline $116 \mathrm{Y}$ & 3 & (3.3) & 2 & $(2.9)$ & 3 & (3.6) & 2 & (3.8) \\
\hline $118 \mathrm{I}$ & 20 & $(21.7)$ & 14 & (20) & 19 & $(22.6)$ & 16 & $(30.2)$ \\
\hline $151 \mathrm{M}$ & 4 & $(4.3)$ & 3 & $(4.3)$ & 4 & $(4.8)$ & 2 & (3.8) \\
\hline $184 \mathrm{I}$ & 2 & $(2.2)$ & 1 & (1.4) & 3 & $(3.6)$ & 3 & (5.7) \\
\hline $184 \mathrm{~V}$ & 56 & $(60.9)$ & 38 & $(54.3)$ & 56 & (66.7) & 29 & $(54.7)$ \\
\hline $210 W$ & 30 & $(32.6)$ & 26 & (37.1) & 28 & (33.3) & 21 & $(39.6)$ \\
\hline $215 \mathrm{~F}$ & 15 & (16.3) & 13 & (18.6) & 14 & (16.7) & 10 & (18.9) \\
\hline $215 \mathrm{Y}$ & 46 & $(50)$ & 38 & $(54.3)$ & 41 & $(48.8)$ & 29 & $(54.7)$ \\
\hline $219 \mathrm{E}$ & 10 & (10.9) & 10 & (14.3) & 9 & (10.7) & 5 & (9.4) \\
\hline $219 \mathrm{~N}$ & 0 & $(0)$ & 1 & $(1.4)$ & 1 & $(1.2)$ & 1 & (1.9) \\
\hline 219Q & 14 & $(15.2)$ & 9 & (12.9) & 13 & (15.5) & 8 & $(15.1)$ \\
\hline 333D & 1 & (1.1) & 0 & $(0)$ & 1 & $(1.2)$ & 0 & $(0)$. \\
\hline $333 \mathrm{E}$ & 7 & $(7.6)$ & 4 & $(5.7)$ & 7 & $(8.3)$ & 6 & $(11.3)$ \\
\hline
\end{tabular}


Table 3. Frequency of mutations according to previous use of NNRTI

\begin{tabular}{|c|c|c|c|c|}
\hline \multirow{3}{*}{$\begin{array}{l}\text { No. Patients } \\
\text { Mutations }\end{array}$} & \multicolumn{4}{|c|}{ NNRTI } \\
\hline & \multicolumn{2}{|c|}{25} & \multicolumn{2}{|c|}{25} \\
\hline & NVP & $(\%)$ & EFZ & $(\%)$ \\
\hline $98 \mathrm{G}$ & 3 & (12) & 1 & (4) \\
\hline 100I & 0 & (0) & 5 & $(20)$ \\
\hline $101 \mathrm{E}$ & 2 & (8) & 1 & (4) \\
\hline $103 \mathrm{~N}$ & 7 & (28) & 8 & (32) \\
\hline $106 \mathrm{~A}$ & 1 & (4) & 0 & (0) \\
\hline 108I & 3 & (12) & 3 & (12) \\
\hline 179D & 0 & (0) & 1 & (4) \\
\hline $181 \mathrm{I}$ & 2 & (8) & 0 & (0) \\
\hline $181 \mathrm{C}$ & 7 & (28) & 2 & (8) \\
\hline $188 \mathrm{~L}$ & 1 & (4) & 1 & (4) \\
\hline 190A & 4 & (16) & 1 & (4) \\
\hline $190 \mathrm{~S}$ & 1 & (4) & 1 & (4) \\
\hline $225 \mathrm{H}$ & 0 & (0) & 0 & (0) \\
\hline
\end{tabular}

patient presented with a wild-type sequence. The most prevalent mutations were 184V, 63P, 215Y, 41L, 36I, 67N, 77I, 90M, 10I, and 210W.

The analysis of an association between previous exposure to antiretroviral drugs and resistance associated mutations show the impact of the use of these drugs in HIV-1 drug resistance [12]. A positive correlation between the number of ARVs previously used and the number of mutations was observed for the NRTI and PI drug classes. This correlation was not seen for NNRTI, due to the characteristics of this class of drug. The presence of only one mutation may lead to crossresistance to all drugs of this class of anti-retroviral drug (Nevirapine, Efavirenz and Delavirdine) and do not allow the use of a second drug after initial failure [13].

The associations detected between mutations and exposure to specific drugs were statistically significant: prior use of D4T was associated with mutations 69D, $118 \mathrm{I}$ and $215 \mathrm{~F} / \mathrm{Y}$; exposure to DDI was associated with mutation $215 \mathrm{~F} / \mathrm{Y}$; and prior use of $3 \mathrm{TC}$ was associated with mutation $184 \mathrm{~V}$. There was a negative association between mutation $184 \mathrm{~V}$ and exposure to
DDI, with a prevalence ratio $=0.3(95 \% \mathrm{CI}: 0.1-0.8)$ and $p$ value $=0.02$. Probably, this is a result of sequential use of ARVs, since DDI has a greater incidence of adverse events and dietary limitations compared to 3TC which is prescribed more frequently as first line therapy [14]. No specific mutation associated with Zidovudine (AZT) was found: this probably reflects the high frequency of previous use of this drug ( $96 \%$ of the patients), so the detection of specific mutations associated with resistance to AZT was not possible.

The evaluation of mutations associated with resistance to NNRTI revealed a significant association between NVP exposure and mutations 98G, 181I and 190A/S, and of previous use of EFZ and mutations $100 \mathrm{I}$ and $103 \mathrm{~N}$. These findings are similar to those described previously [15].

Specific mutations associated with PI resistance were found in patients previously exposed to this class of drug. Previous exposure to Nelfinavir (NFV) was associated with mutations 30N, 88D and 90M ( $p<0.05$ for each). Exposure to Saquinavir (SQV) was associated with mutations $53 \mathrm{~L}, 71 \mathrm{~V}, 73 \mathrm{~S}$ and 
Table 4. Frequency of mutations according to previous use of PI

\begin{tabular}{|c|c|c|c|c|c|c|c|c|}
\hline \multirow{3}{*}{$\begin{array}{l}\text { No. patients } \\
\text { Mutations }\end{array}$} & \multicolumn{8}{|c|}{ PI } \\
\hline & \multicolumn{2}{|c|}{51} & \multicolumn{2}{|c|}{44} & \multicolumn{2}{|c|}{19} & \multicolumn{2}{|c|}{33} \\
\hline & IDV & $(\%)$ & NFV & $(\%)$ & SQV & $(\%)$ & RTV & $(\%)$ \\
\hline $10 \mathrm{~F}$ & 5 & (9.8) & 5 & (11.4) & 1 & $(5.3)$ & 3 & (9.1) \\
\hline $10 \mathrm{I}$ & 28 & $(54.9)$ & 13 & $(29.5)$ & 11 & $(57.9)$ & 19 & $(57.6)$ \\
\hline $10 \mathrm{~V}$ & 4 & $(7.8)$ & 4 & $(9.1)$ & 2 & $(10.5)$ & 4 & (12.1) \\
\hline $20 \mathrm{M}$ & 1 & $(2.0)$ & 1 & $(2.3)$ & 2 & (10.5) & 2 & (6.1) \\
\hline $20 \mathrm{R}$ & 9 & (17.6) & 2 & $(4.5)$ & 3 & (15.8) & 6 & (18.2) \\
\hline $24 \mathrm{I}$ & 4 & $(7.8)$ & 2 & $(4.5)$ & 0 & (0) & 2 & (6.2) \\
\hline $30 \mathrm{~N}$ & 3 & $(5.9)$ & 13 & $(29.5)$ & 1 & $(5.3)$ & 1 & (3) \\
\hline $32 \mathrm{I}$ & 4 & $(7.8)$ & 0 & $(0)$ & 0 & $(0)$ & 3 & (9.1) \\
\hline $36 \mathrm{I}$ & 24 & $(47.1)$ & 20 & $(45.5)$ & 10 & $(52.6)$ & 19 & $(57.6)$ \\
\hline $46 \mathrm{I}$ & 15 & $(29.4)$ & 6 & (13.6) & 6 & $(31.6)$ & 11 & (33.3) \\
\hline $46 \mathrm{~L}$ & 5 & $(9.8)$ & 4 & $(9.1)$ & 1 & $(5.3)$ & 1 & (3) \\
\hline $47 \mathrm{~V}$ & 2 & (3.9) & 0 & $(0)$ & 0 & $(0)$ & 0 & (0) \\
\hline $48 \mathrm{~V}$ & 6 & (11.8) & 3 & (6.8) & 4 & $(21.1)$ & 4 & (12.1) \\
\hline 50 & 0 & $(0)$ & 0 & $(0)$ & 0 & $(0)$ & 0 & $(0)$ \\
\hline $53 \mathrm{~L}$ & 8 & (15.7) & 2 & $(4.5)$ & 5 & (26.3) & 6 & $(18.2)$ \\
\hline $54 \mathrm{I}$ & 1 & (2) & 0 & (0) & 0 & $(0)$ & 1 & (3) \\
\hline $54 \mathrm{~L}$ & 1 & (2) & 0 & (0) & 1 & $(5.3)$ & 2 & (6.1) \\
\hline $54 \mathrm{~T}$ & 2 & $(3.9)$ & 0 & $(0)$ & 1 & $(5.3)$ & 1 & (3) \\
\hline $54 \mathrm{~V}$ & 16 & (31.4) & 7 & (15.9) & 6 & (31.6) & 12 & $(36.4)$ \\
\hline $63 \mathrm{~L}$ & 0 & $(0)$ & 1 & $(2.3)$ & 0 & (0) & 1 & (3) \\
\hline $63 \mathrm{P}$ & 27 & $(52.9)$ & 22 & $(50)$ & 7 & $(36.8)$ & 16 & $(48.5)$ \\
\hline $71 \mathrm{I}$ & 1 & (2) & 0 & $(0)$ & 1 & $(5.3)$ & 1 & (3) \\
\hline $71 \mathrm{~T}$ & 3 & $(5.9)$ & 6 & (13.6) & 2 & $(10.5)$ & 2 & (6.1) \\
\hline $71 \mathrm{~V}$ & 20 & (39.2) & 8 & (18.2) & 8 & $(42.1)$ & 13 & $(39.4)$ \\
\hline $73 \mathrm{~S}$ & 6 & (11.8) & 1 & $(2.3)$ & 3 & (15.8) & 4 & (12.1) \\
\hline 77I & 17 & (33.3) & 18 & (40.9) & 6 & (31.6) & 8 & $(24.2)$ \\
\hline $82 \mathrm{~A}$ & 20 & (39.2) & 5 & (11.4) & 6 & (31.6) & 15 & $(45.5)$ \\
\hline $82 \mathrm{~T}$ & 1 & (2) & 0 & (0) & 0 & $(0)$ & 1 & (3) \\
\hline $84 \mathrm{~N}$ & 0 & $(0)$ & 0 & $(0)$ & 0 & $(0)$ & 1 & (3) \\
\hline $84 \mathrm{~V}$ & 12 & $(23.5)$ & 3 & $(6.8)$ & 8 & $(42.1)$ & 10 & $(30.3)$ \\
\hline $88 \mathrm{D}$ & 4 & $(7.8)$ & 11 & (25) & 1 & $(5.3)$ & 1 & (3) \\
\hline $88 \mathrm{~N}$ & 0 & $(0)$ & 0 & $(0)$ & 0 & $(0)$ & 1 & (3) \\
\hline $90 \mathrm{M}$ & 24 & $(47.1)$ & 13 & $(29.5)$ & 14 & (73.7) & 19 & $(57.6)$ \\
\hline $90 \mathrm{~N}$ & 0 & (0) & 0 & (0) & 0 & $(0)$ & 1 & (3) \\
\hline $93 \mathrm{~N}$ & 0 & $(0)$ & 0 & $(0)$ & 0 & (0) & 1 & (3) \\
\hline
\end{tabular}


Figure 1. Mean frequency of mutations according to the number of NRTI previously used $(\mathrm{p}=0.027)$

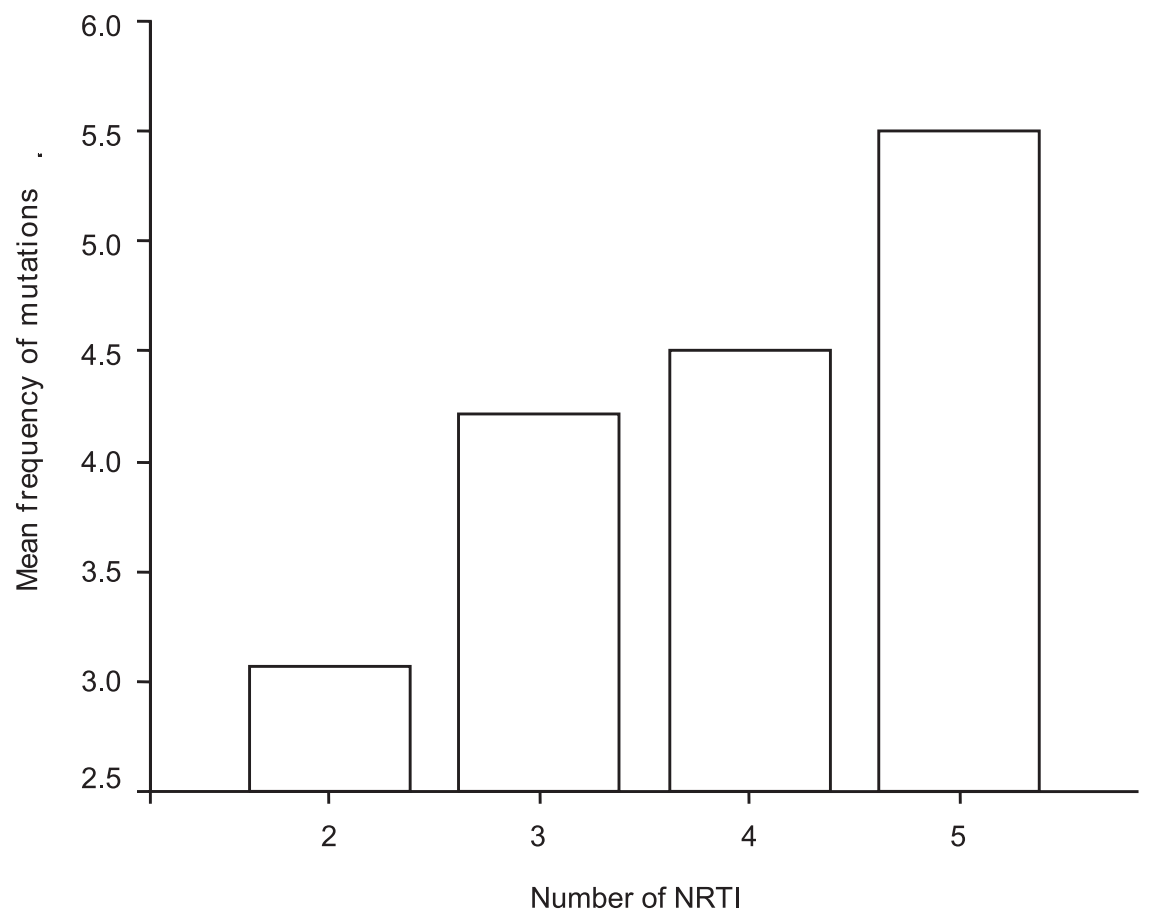

Table 5. Mutations significantly associated with previous use of NRTI

\begin{tabular}{llcc}
\hline Mutation & ARV & PR $(\mathbf{9 5 \%} \mathbf{C I})$ & $\mathbf{p}$ \\
\hline $69 \mathrm{D}$ & D4T & $7.4(0.9-62)$ & 0.02 \\
$118 \mathrm{I}$ & D4T & $3.3(1-10)$ & 0.02 \\
$184 \mathrm{~V}$ & DDI & $0.3(0.1-0.8)$ & 0.02 \\
$184 \mathrm{~V}$ & $3 \mathrm{TC}$ & $26(3-212)$ & 0.00 \\
$215 \mathrm{~F} / \mathrm{Y}$ & D4T & $2.2(0.9-5.2)$ & 0.05 \\
$215 \mathrm{~F} / \mathrm{Y}$ & DDI & $3(1.2-7.9)$ & 0.01 \\
\hline
\end{tabular}

PR - Prevalence ratio.

Table 6. Mutations significantly associated with previous exposure to NRTI

\begin{tabular}{lccc}
\hline Mutation & ARV & PR $(\mathbf{9 5 \%}$ CI $)$ & p \\
\hline $98 \mathrm{G}$ & NVP & -0.016 & \\
$100 \mathrm{I}$ & EFV & -0.001 & \\
$103 \mathrm{~N}$ & EFV & $2.8(0.0-8.4)$ & 0.051 \\
$181 \mathrm{I} / \mathrm{C}$ & NVP & $19.4(3.8-98.6)$ & $<0.001$ \\
$190 \mathrm{~A} / \mathrm{S}$ & NVP & $17.5(1.9-158)$ & $<0.001$ \\
\hline
\end{tabular}

PR - Prevalence ratio. 
Table 7. Mutations significantly associated to previous PI use

\begin{tabular}{|c|c|c|c|}
\hline Mutation & ARV & PR (95\% CI) & $\mathbf{p}$ \\
\hline $10 \mathrm{I} / \mathrm{F} / \mathrm{V}$ & IDV & $4.3(1.8-10)$ & 0.001 \\
\hline $10 \mathrm{I} / \mathrm{F} / \mathrm{V}$ & RTV & $4.6(1.7-12)$ & 0.001 \\
\hline $20 \mathrm{M} / \mathrm{R}$ & NFV & $0.24(0.064-0.9)$ & 0.026 \\
\hline $30 N$ & NFV & $6.8(1.8-26)$ & 0.002 \\
\hline $30 N$ & IDV & $0.1(0.04-0.5)$ & 0.003 \\
\hline $30 N$ & RTV & $0.1(0.01-0.8)$ & 0.007 \\
\hline $46 \mathrm{I} / \mathrm{L}$ & IDV & $2.9(1-7)$ & 0.018 \\
\hline $53 \mathrm{~L}$ & SQV & $6.5(1.5-27)$ & 0.014 \\
\hline $53 \mathrm{~L}$ & IDV & $8(0.9-68)$ & 0.024 \\
\hline $53 \mathrm{~L}$ & RTV & $4.4(1-19)$ & 0.04 \\
\hline $53 \mathrm{~L}$ & LPV & $12(1.5-99)$ & 0.04 \\
\hline $54 \mathrm{~V}$ & $\mathrm{NFV}$ & $0.3(0.1-0.9)$ & 0.03 \\
\hline $54 \mathrm{~V}$ & IDV & $5.1(1.7-15)$ & 0.002 \\
\hline $54 \mathrm{~V}$ & RTV & $5.6(2.1-15)$ & 0.000 \\
\hline $54 \mathrm{~V}$ & APV & $9.5(0.9-96)$ & 0.05 \\
\hline $71 \mathrm{~V}$ & SQV & $2.8(1-7.9)$ & 0.038 \\
\hline $71 \mathrm{~V}$ & IDV & $2.4(1-5.7)$ & 0.032 \\
\hline $73 \mathrm{~S}$ & SQV & $7.2(2.1-24)$ & 0.002 \\
\hline $73 \mathrm{~S}$ & LPV & $17(2-150)$ & 0.026 \\
\hline $82 \mathrm{~A}$ & NFV & $0.1(0.06-0.5)$ & 0.001 \\
\hline $82 \mathrm{~A}$ & IDV & $5.6(1.8-16)$ & 0.001 \\
\hline $82 \mathrm{~A}$ & RTV & $5(2-13)$ & 0.001 \\
\hline $84 \mathrm{~V}$ & NFV & $0.2(0.06-0.9)$ & 0.026 \\
\hline $84 \mathrm{~V}$ & IDV & $4.3(1-16)$ & 0.021 \\
\hline $84 \mathrm{~V}$ & RTV & $7.3(2-26)$ & 0.001 \\
\hline $84 \mathrm{~V}$ & APV & $20(1.9-208)$ & 0.01 \\
\hline $88 \mathrm{D}$ & NFV & $4(1-14)$ & 0.02 \\
\hline $88 \mathrm{D}$ & IDV & $0.2(0.07-0.8)$ & 0.025 \\
\hline $90 \mathrm{M}$ & NFV & $10(1.6-59)$ & 0.013 \\
\hline $90 \mathrm{M}$ & SQV & $7(2.2-22)$ & 0.000 \\
\hline $90 \mathrm{M}$ & IDV & $2.4(1-57)$ & 0.032 \\
\hline $90 \mathrm{M}$ & RTV & $4.5(1,8-11)$ & 0.001 \\
\hline
\end{tabular}

PR - Prevalence ratio.

90M and mutations 10I, 46I, 53D, 54V, 71V, 82A, $84 \mathrm{~V}, 88 \mathrm{D}$ and $90 \mathrm{M}$ were associated with previous use of Indinavir (IDV). Mutations 53L and 88D are associated with use of Ritonavir (RTV) and Nelfinavir, respectively, as we found in this study. Mutations 10I, $53 \mathrm{~L}, 54 \mathrm{~V}, 82 \mathrm{~A}, 84 \mathrm{~V}$ and $90 \mathrm{M}$ were significantly associated with resistance to Ritonavir, confirming the available data [16-18].

Despite the low frequency of use of Amprenavir (APV) and Lopinavir (LPV), some mutations were significantly associated with previous exposure to these drugs. Although mutations $54 \mathrm{~V}$ and $84 \mathrm{~V}$ are 
Figure 2. Mean frequency of mutations according to the number of PI previously used ( $\mathrm{p}=0.001)$

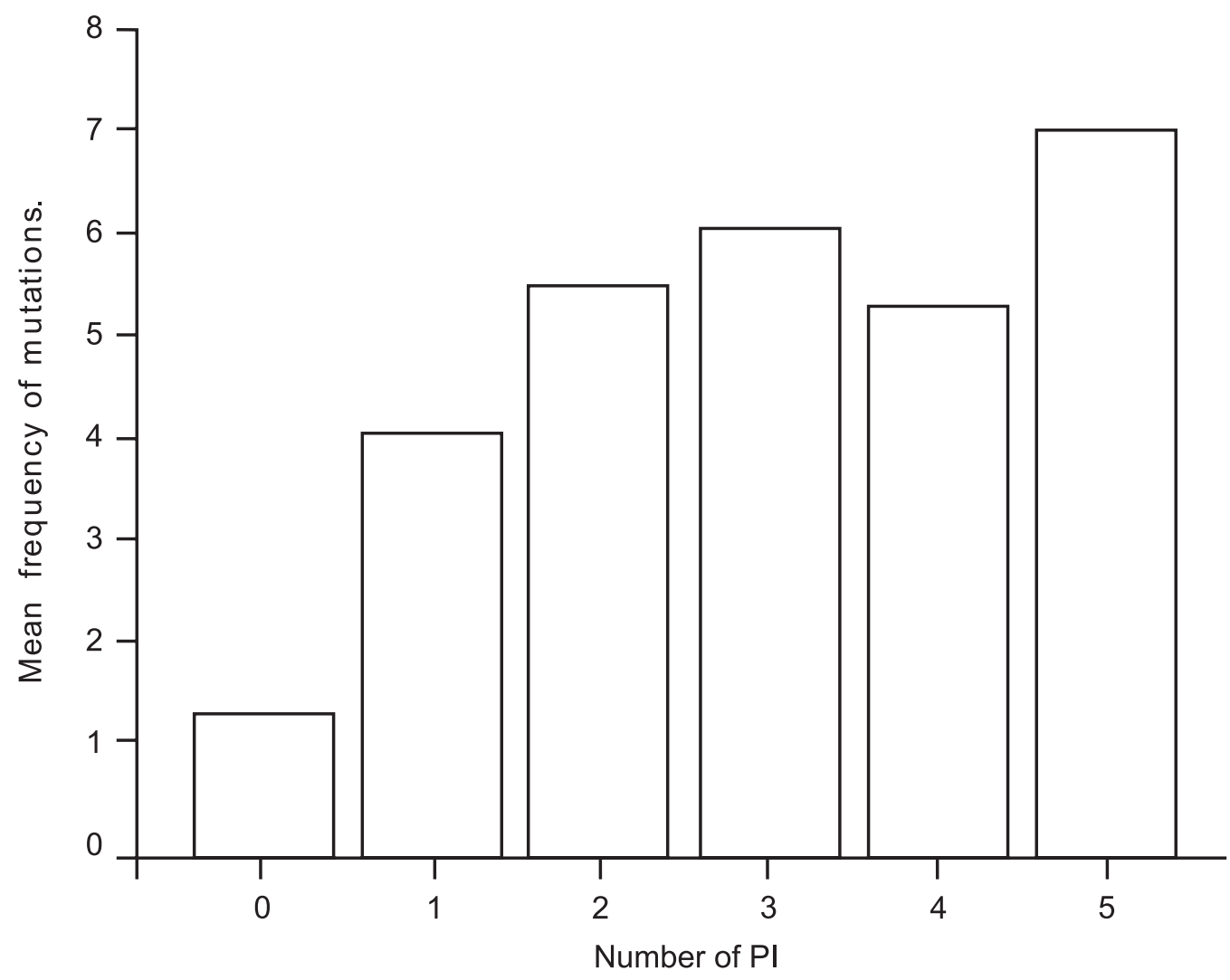

not induced only by these drugs, the high value of the prevalence ratio (PR) suggests a strong association between some mutations and these ARVs: APV and 84V - PR=20 (95\%CI: 1.9-208); IDV and $84 \mathrm{~V}-\mathrm{PR}=4.3$ (95\% CI:1-16); RTV and $84 \mathrm{~V}-\mathrm{PR}=7.3$ (95\% CI: 2-26). Mutations 53L and $73 \mathrm{~S}$ were associated with previous exposure to LPV/ $\mathrm{r}(\mathrm{PR}=12,95 \% \mathrm{CI}(1.5-99)$ and $\mathrm{PR}=17,95 \% \mathrm{CI}(2-$ 150) respectively), but these mutations are also reported to be associated with RTV (53L), and SQV or IDV (73S) [11]. Again, the higher PR observed in the analysis of mutations associated with $\mathrm{LPV} / \mathrm{r}$, suggest a potential role for induction by this drug. We cannot discard a cumulative effect due to sequential use of these protease inhibitors during therapy, even though the criteria of RENAGENO excluded genotyping in patients failing more than two regimes containing PIs.
HIV drug resistance is the main cause of virological and clinical failure in HIV-1 infected patients [1,19]. The results of this study revealed the impact of HIV-1 genotypic resistance on prognostic markers $\left(\mathrm{CD}_{4}\right.$ count and viral load). Viral load mean before treatment (log 4.85 RNA copies) decreases after the initiation of HAART $(\log 4.13)$, reaching the lowest value during treatment $(\log 3.41)$. However, after treatment failure, mean viral load returned to baseline values $(\log 4.67)$, as a consequence of the loss of activity of anti-retroviral drugs. An inverse correlation was observed between $\mathrm{CD}_{4}$ counts and therapy failure: there was an increase of 101 cells $/ \mathrm{mm}^{3}$ after HAART, with return to baseline values after treatment failure.

In Brazil, there is little data on HIV-1 drug resistance [20-24]. It is important to evaluate the prevalence rate and mutation pattern for drugs in both naive and treated patients, in order to design better strategies that make 
better management of antiretroviral therapy possible. This study provides some insights on this kind of problem, and it adds some new information about the potential impact of the introduction of genotyping as a strategy to recognize and minimize drug resistance among AIDS patients under therapy.

\section{Acknowledgments}

The authors thank to Dr. Paulo Roberto de Oliveira Costa from the State of Sergipe, for giving us access to three patients from that state.

\section{References}

1. Moyle G.J. Resistance to antiretroviral compounds: implications for the clinical management of HIV infection. Imuunol \& Infec Dis 1995;5:170-82.

2. Condra J.H., Emini EA. Preventing HIV-1 Drug Resistance. Science \& Medicine, 1997; Jan-Feb:2-11.

3. Larder B.A., Kemp S.D. Multiple mutations in HIV-1 reverse transcriptase confer high-level resistance to Zidovudine (AZT). Science 1989;246:1155-8.

4. Iversen A.K.N., Shafer R.W., Wehrly K., et al. Multidrugresistant human immunodeficiency virus type I strains resulting from combination antiretroviral therapy. J Virol 1996;70(2):1086-90.

5. Durant J., Clevenbergh P., Halfon P., et al. Drugresistance genotyping in HIV-1 therapy: the VIRAD APT randomized controlled trial. Lancet 1999;353:2195-9.

6. Meynard J.-L., Vray M., Morand-Joubert L., et al. Phenotypic and genotypic resistance testing for choosing antiretroviral therapy after treatment failure: a randomized trial. AIDS 2002;16:727-36.

7. Hirsch M.S., Conway B., D'Aquila R.T., et al. Antiretroviral drug resistance testing in adults with HIV infection. Implications for clinical management. JAMA 1998;279(24):1984-91.

8. Ruiz L. Interpreting resistance test results to optimize treatment regimens. Advanced Studies in Medicine 2002;2(23):823-6.

9. Mayers D.L. Prevalence and incidence of resistance to Zidovudine and other antiretroviral drugs. Am J Med 1997;102(5B):70-5.

10. Coffin J.M. HIV population dynamics in vivo: implications for genetic variation, pathogenesis and therapy. Science 1995;267:483-9.
11. Clotet B., Menendez-Arias L., Ruiz L., et al. Guide to management of HIV drugs resistance and pharmacokinetics of antiretroviral therapy. 2 edition, Editora TAISA, 2002, pp 269.

12. Villalba N., Gómez-Cano M., Holguin A., et al. Multiple drug resistance genotype causing failure of antiretroviral treatment in an HIV-infected patient heavily exposed to nucleoside analogues. Eur J Clin Microbiol Infect Dis 1999;18:372-5.

13. Casado J.L., Hertogs K., Ruiz L., et al. Non-nucleoside reverse transcriptase inhibitor resistance among patients failing a nevirapine plus protease inhibitorcontaining regimen. AIDS 2000;14(2):F1-F7.

14. Carpenter C.C.J., CooperD.A., Fischl M.A., et al. Antiretroviral therapy in adults. Update recommendations of the international AIDS Society-USA Panel. JAMA 2000;283(3):381-91.

15. Deeks S.G. Nonnucleoside reverse transcriptase inhibitor resistance. JAIDS 2001;26:S25-S33.

16. Race E., Dam E., Obry V., et al. Analysis of HIV crossresistance to protease inhibitors using a rapid singlecycle recombinant virus assay for patients failing on combination therapies. AIDS 1999;13:2061-8.

17. Miller V. Resistance to protease inhibitors. JAIDS 2001;26:S34-S50.

18. D'Aquila R.T., Schapiro J.M., Brun-Vézinet F., et al. Drug resistance mutations in HIV-1. Inter AIDS Society-USA 2002;10(5):21-5.

19. Rizzardi G.P., de Boer R.J., Hoover S., et al. Predicting the duration of antiviral treatment needed to suppress plasma HIV-1 RNA. J Clin Invest 2000;105(6):777-82.

20. Dumans A.T., Soares M.A., Pieniazek D., et al. Prevalence of protease and reverse transcriptase drug resistance mutations over time in drug-naïve Human Immunodeficiency Virus type -1 positive individuals in Rio de Janeiro, Brazil. Antimicrob Agents Chemother 2002;46(9):3075-9.

21. Sucupira M.C., Souza I.E., Costa L.J., et al. Antiretroviral treatment failure and HIV-1 genotypic resistance in São Paulo, Brazil. Antivir Ther 2001;6(4):263-4.

22. Tanuri A., Caridea E., Dantas M.C., et al. Prevalence of mutations related to HIV-1 antiretroviral resistant in Brazilian patients failing HAART. J Clin Virol 2002;25(1):39-46.

23. Brindeiro R., Vanderborght B., Caride E., et al. Sequence diversity of the reverse transcriptase of human immunodeficiency virus type 1 from untreated Brazilian individuals. Antimicrob Agents Chemother, 1999;43(7):1674-80.

24. Brites C., Bahia F., Gilbert M., et al. Evaluation of viral resistance to reverse transcriptase inhibitors (RTI) in HIV-1 infected patients before and after 6 months of single or double antiretroviral therapy. Braz J Infect Dis 2001;5(4):177-82. 